\title{
Lung Adenocarcinoma with Pulmonary Miliary Metastases and Complex Somatic Heterozygous EGFR Mutation
}

\author{
Alexandre Schaller ${ }^{a} \quad$ Michèle Beau-Faller $^{c} \quad$ Bertrand Mennecier $^{a}$ \\ Benjamin Renaud-Picard $^{a} \quad$ Noëlle Weingertner ${ }^{d} \quad$ Gilbert Massard $^{b}$ \\ Elisabeth Quoix ${ }^{a}$
}

Departments of ${ }^{a}$ Chest Diseases and ${ }^{b}$ Thoracic Surgery, University Hospital of Strasbourg, and Departments of ${ }^{\mathrm{C}}$ Molecular Biology and ${ }^{\mathrm{d}}$ Pathology, University Hospital of Strasbourg, Hôpital de Hautepierre, Strasbourg, France

\section{Key Words}

EGFR mutations - Lung miliary metastases - EGFR-tyrosine kinase inhibitor primary resistance . Non-small cell lung cancer · Lung adenocarcinoma

\section{Abstract}

The pretreatment detection of an activating mutation of EGFR is now routinely performed in metastatic nonsquamous non-small cell lung cancer (NSCLC). The therapeutic impact of such a detection is major, as patients with advanced NSCLC exhibiting a mutation of exon 19 or 21 will benefit from EGFR-tyrosine kinase inhibitors (TKI). The presence of an EGFR resistance mutation, such as T790M in EGFR-TKI-naïve patients, is seldom looked for and is related either to a germinal mutation or to somatically mutated subclones. It has a negative predictive impact. We present the case of a patient with a lung papillary adenocarcinoma and miliary intrapulmonary metastases whose tumor displays a somatic complex heterozygous EGFR mutation, combining L858R (exon 21) and a primary resistance mutation T790M (exon $20)$, both detected by direct sequencing.

\section{Introduction}

The best-characterized mutations of EGFR conferring sensitivity to EGFR-tyrosine kinase inhibitors (TKI) in non-small cell lung cancer (NSCLC) are deletions in exon 19 (Del 19)

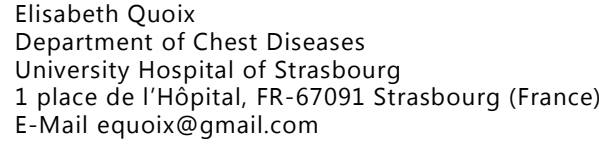


and point mutations in exon 21 (L858R). Conversely, the most common mutation conferring resistance to EGFR-TKI is the exon 20 point mutation (T790M) [1].

This T790M mutation is considered the major cause of acquired resistance to EGFR-TKI. Primary T790M mutation can also occur at baseline (before TKI treatment) related to a germinal mutation or somatically mutated subclones [2].

A recent meta-analysis of the predictive role of a pretreatment T790M mutation in patients with activating EGFR mutation receiving EGFR-TKI treatment shows that the pretreatment T790M mutation has a negative impact on progression-free survival [3].

Here, we present the case of a young patient with a primary lung papillary adenocarcinoma and miliary pulmonary metastases, diagnosed with pretreatment complex EGFR mutation combining a heterozygous somatic L858R mutation and T790M mutation.

\section{Case Description}

A 47-year-old man presented with a history of weight loss from 97 to $92 \mathrm{~kg}$ within 1 month, cough and fatigue. A chest X-ray (fig. 1) showed bilateral multiple micronodules described as miliary. The patient had no fever, and his oxygen saturation was $90 \%$ (rest time without oxygen), improving to $94 \%$ under oxygenotherapy (1 liter/min). His performance status was 2. Clinical examination was otherwise normal.

Thoracic CT scan (fig. 2) confirmed miliary metastases and a nodule in the right middle lobe and revealed bilateral mediastinal lymph nodes. No other metastasis was found on cerebral MRI or abdominopelvic CT scan. Bronchoscopy was macroscopically normal, but cytology of bronchoalveolar lavage (BAL) highlighted an adenocarcinoma, which was confirmed as papillary subtype by mediastinoscopy. The clinical stage was therefore T1aN3M1a.

Molecular analysis of BAL, containing $30 \%$ of tumor cells, by direct sequencing showed a somatic complex heterozygous EGFR mutation (fig. 3) composed of L858R mutation in exon 21 and T790M mutation in exon 20. T790M was confirmed to be somatic, as it was not detected in the paired lymphocytes of the patient.

We started a treatment with erlotinib $(150 \mathrm{mg} /$ day orally). After 15 days, the patient returned with worsened dyspnea and an oxygen saturation of $87 \%$ with 2 liters/min oxygen. He had a grade 3 acneiform rash on the face and the chest. Chest X-ray showed worsening of the miliary metastases. Erlotinib was stopped, and chemotherapy with cisplatin-pemetrexed and bevacizumab was introduced. After the first cycle of chemotherapy, there was a dramatic improvement in oxygen saturation (96\% without oxygenotherapy) and regression of the miliary metastases.

\section{Discussion}

EGFR exon 20 insertions account for 4\% of EGFR mutations and are associated with a lack of sensitivity to EGFR-TKI in preclinical models and in patients [2-4]. Another mutation in exon 20 conferring resistance involves a substitution of methionine for threonine at position $790(\mathrm{~T} 790 \mathrm{M})$. This alteration is found as a germ-line variant in $0.5 \%$ of neversmokers with lung adenocarcinoma [5] and may confer genetic susceptibility to lung cancer [6]. In fact, EGFR germinal mutations are not looked for in routine practice.

In the natural history of the disease, T790M mutation could be present in a small subset of tumor cells and expand selectively under EGFR-TKI, leading to more than $50 \%$ percent of 
secondary resistance. The frequency of somatic T790M mutation at baseline (before TKI treatment) is controversial, and detection depends on the sensitivity of the molecular technique. Studies have suggested that pre-existing resistance may be present at a very low frequency [6-8].

A study found $1(0.54 \%)$ EGFR T790M mutation among 185 NSCLC patients without EGFR-TKI treatment, using mutant-enriched PCR analysis, but not confirmed by direct sequencing [7]. Others have found frequencies of up to $35 \%$ with very high-sensitive molecular techniques [9-11]. Usually, T790M could not be detected by direct sequencing because of lack of sensitivity. One study reported $2(0.83 \%)$ cases harboring the EGFR T790M mutation among 240 patients with EGFR-TKI-naïve lung adenocarcinoma detected by sequencing but, contrarily to our case, with both germ-line and somatic T790M mutation and without any other EGFR mutation [12].

T790M mutation impairs the binding of EGFR-TKI to the EGFR adenosine triphosphatebinding pocket, and emerging data suggest that T790M change itself may potentiate oncogenic activation. Patients whose tumors harbor somatic T790M mutations before treatment had a shorter progression-free survival [9-11]. We underline the clinical importance of pretreatment T790M mutation detection because the response to EGFR-TKI is less certain and could lead to a delay in the introduction of classical platinum-based chemotherapy.

Diffuse, random pulmonary metastases, including miliary metastases, are quite a rare presentation in NSCLC and seem to be associated with adenocarcinoma subtype and EGFR mutation, suggesting that EGFR-TKI may be the treatment of choice for such patients especially in the Asian population [13-15]. A study reported 5 cases of never-smokers with lung adenocarcinoma with such a pattern of metastases [16]. In the tumor cells of all 5 patients, EGFR mutation gene sequencing identified a deletion in exon 19, and all 5 patients had a dramatic response to EGFR-TKI.

No T790M mutation has been reported. In fact, clinical data about patients with lung adenocarcinoma harboring EGFR T790M mutations at diagnosis are not described.

\section{Conclusion}

This case highlights the link between an uncommon radiological presentation of adenocarcinoma (miliary pattern) and the clinical importance of the detection of a pretreatment (baseline) T790M mutation in NSCLC patients with an activating EGFR mutation.

\section{References}

1 Massarelli E, Johnson FM, Erickson HS, et al: Uncommon epidermal growth factor receptor mutations in non-small cell lung cancer and their mechanisms of EGFR tyrosine kinase inhibitors sensitivity and resistance. Lung Cancer 2013;80:235-241.

2 Beau-Faller M, Prim N, Ruppert AM, et al: EGFR exon 18 and exon 20 mutations in non-small-cell lung cancer on 10,117 patients: a multicentre observational study by the French ERMETIC-IFCT network. Ann Oncol 2014;25:126-131.

3 Ding D, Yu Y, Li Z, et al: The predictive role of pretreatment epidermal growth factor receptor T790M mutation on the progression-free survival of tyrosine-kinase inhibitor-treated non-small cell lung cancer patients: a meta-analysis. Onco Targets Ther 2014;7:387-393.

-4 Yasuda H, Kobayashi S, Costa DB: EGFR exon 20 insertion mutations in non-small-cell lung cancer: preclinical data and clinical implications. Lancet Oncol 2012;13:e23-e31.

$>5$ Girard N, Lou E, Azzoli CG, et al: Analysis of genetic variants in never-smokers with lung cancer facilitated by an Internet-based blood collection protocol: a preliminary report. Clin Cancer Res 2010;16:755-763. 


\section{Case Reports in Oncology}

\begin{tabular}{l|l}
\hline Case Rep Oncol 2014;7:769-773 \\
\hline DOI: $10.1159 / 000369526$ & $\begin{array}{l}\text { (c) 2014 S. Karger AG, Basel } \\
\text { www.karger.com/cro }\end{array}$ \\
\hline
\end{tabular}

Schaller et al.: Lung Adenocarcinoma with Pulmonary Miliary Metastases and Complex Somatic Heterozygous EGFR Mutation

6 Bell DW, Gore I, Okimoto RA, et al: Inherited susceptibility to lung cancer may be associated with the T790M drug resistance mutation in EGFR. Nat Genet 2005;37:1315-1316.

7 Inukai M, Toyooka S, Ito S, et al: Presence of epidermal growth factor receptor gene T790M mutation as a minor clone in non-small cell lung cancer. Cancer Res 2006;66:7854-7858.

$>8$ Chmielecki J, Foo J, Oxnard GR, et al: Optimization of dosing for EGFR-mutant non-small cell lung cancer with evolutionary cancer modeling. Sci Transl Med 2011;3:90ra59.

9 Maheswaran S, Sequist LV, Nagrath S, et al: Detection of mutations in EGFR in circulating lung-cancer cells. N Engl J Med 2008;359:366-377.

10 Rosell R, Molina MA, Costa C, et al: Pretreatment EGFR T790M mutation and BRCA1 mRNA expression in erlotinib-treated advanced non-small-cell lung cancer patients with EGFR mutations. Clin Cancer Res 2011;17:1160-1168.

11 Su KY, Chen HY, Li KC, et al: Pretreatment epidermal growth factor receptor (EGFR) T790M mutation predicts shorter EGFR tyrosine kinase inhibitor response duration in patients with non-small-cell lung cancer. J Clin Oncol 2012;30:433-440.

$\checkmark 12$ Prudkin L, Tang X, Wistuba II: Germ-line and somatic presentations of the EGFR T790M mutation in lung cancer. J Thorac Oncol 2009;4:139-141.

13 Togashi Y, Masago K, Kubo T, et al: Association of diffuse, random pulmonary metastases, including miliary metastases, with epidermal growth factor receptor mutations in lung adenocarcinoma. Cancer 2011;117:819-825.

14 Jayaram Subhashchandra B, Ismailkhan M, Chikkaveeraiah Shashidhar K, et al: A rare case of non-small cell carcinoma of lung presenting as miliary mottling. Iran J Med Sci 2013;38:65-68.

15 Wu SG, Hu FC, Chang YL, et al: Frequent EGFR mutations in nonsmall cell lung cancer presenting with miliary intrapulmonary carcinomatosis. Eur Respir J 2013;41:417-424.

16 Laack E, Simon R, Regier M, et al: Miliary never-smoking adenocarcinoma of the lung: strong association with epidermal growth factor receptor exon 19 deletion. J Thorac Oncol 2011;6:199-202.

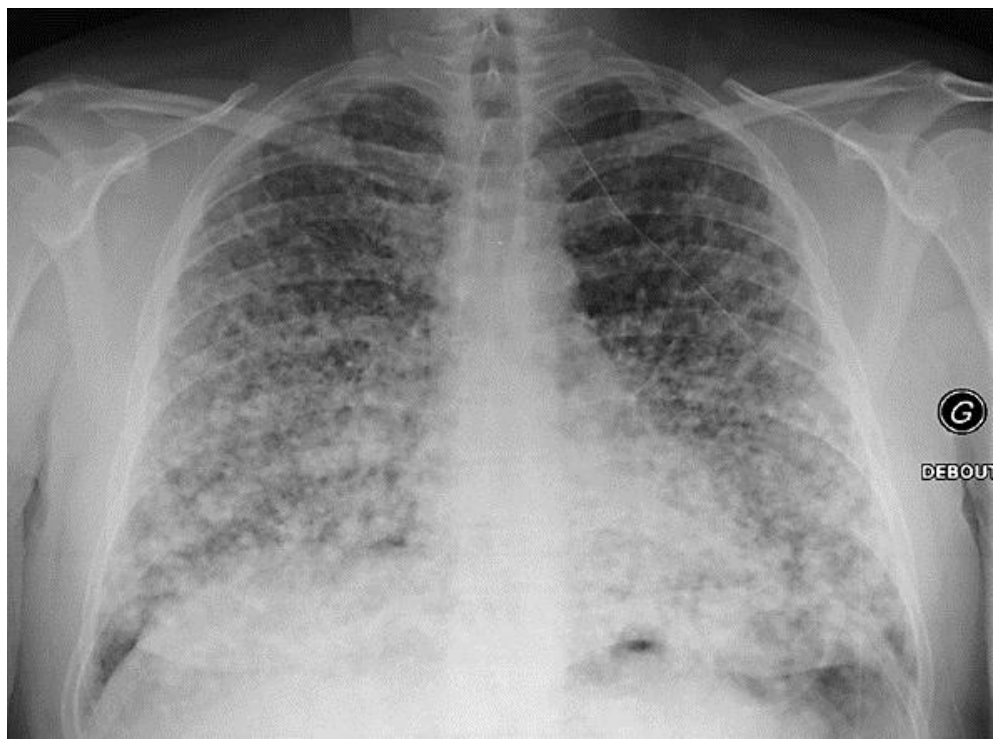

Fig. 1. Chest X-ray showing miliary mottling. 
Schaller et al.: Lung Adenocarcinoma with Pulmonary Miliary Metastases and Complex Somatic Heterozygous EGFR Mutation

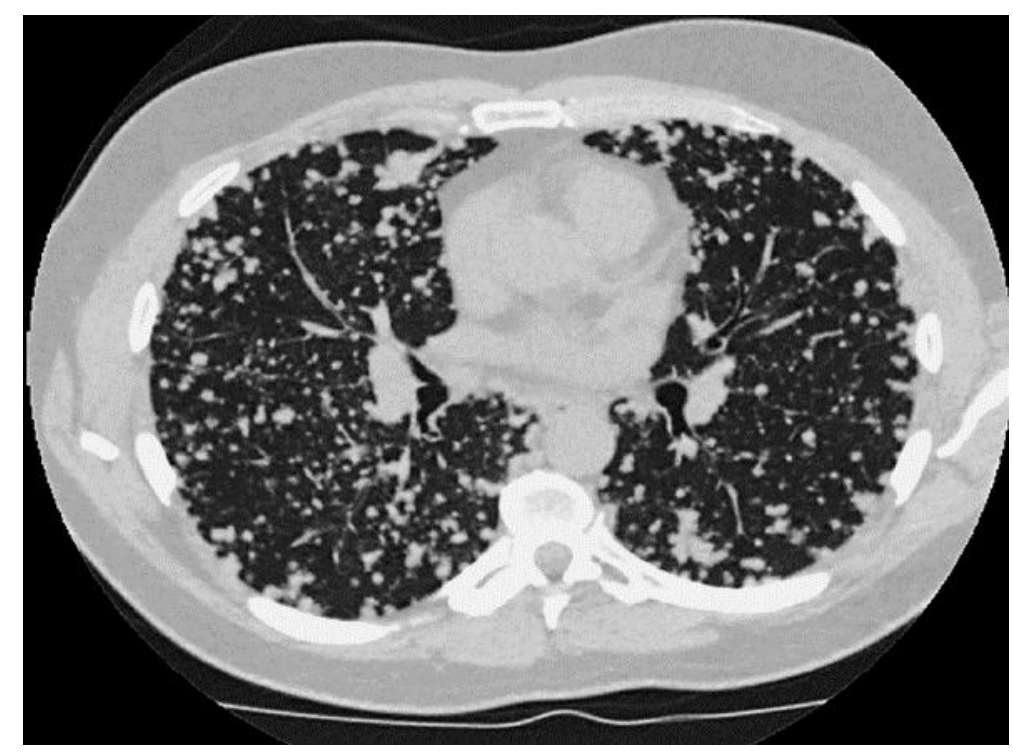

Fig. 2. Thoracic CT scan with primary tumor in the middle lobe and miliary metastatic pattern.
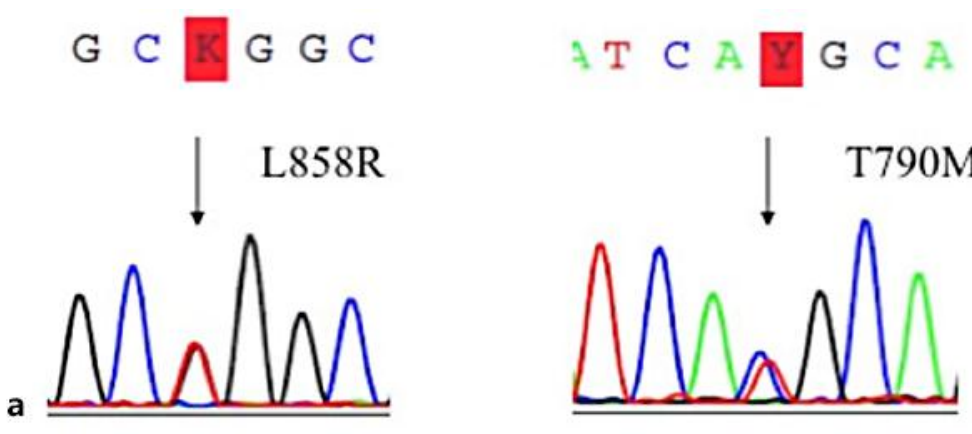

G C T G G C
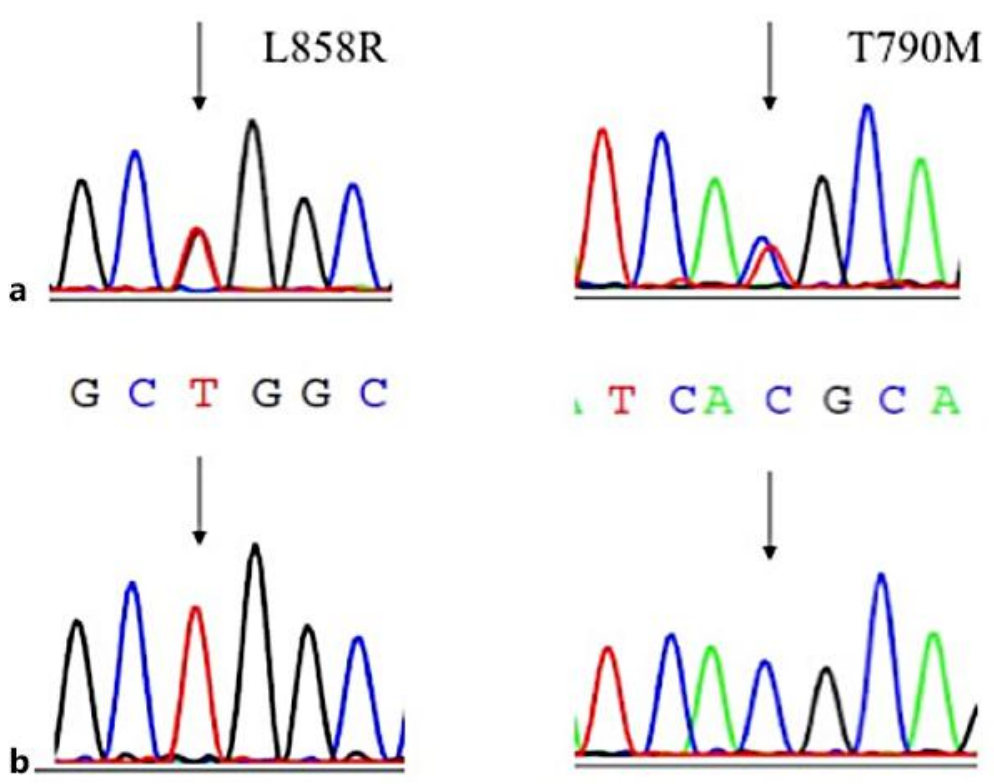

Fig. 3. DNA sequencing electropherograms for DNA obtained a from lung tumor tissue (BAL with $30 \%$ tumor cells), identifying two heterozygous somatic EGFR mutations [L858R (exon 21) and T790M (exon 20 )] and $\mathbf{b}$ from blood, without identifying EGFR mutation. 